\title{
Unveiling a novel biomarker panel for diagnosis and classification of well-differentiated thyroid carcinomas
}

\author{
N. MONIQUE PARICHARTTANAKUL ${ }^{1}$, KITTIRAT SAHARAT ${ }^{2}$, DARANEE CHOKCHAICHAMNANKIT ${ }^{1}$, \\ PHAIBUL PUNYARIT $^{3}$, CHANTRAGAN SRISOMSAP ${ }^{1}$ and JISNUSON SVASTI $^{1,2}$ \\ ${ }^{1}$ Laboratory of Biochemistry, Chulabhorn Research Institute; ${ }^{2}$ Applied Biological Sciences Program, \\ Chulabhorn Graduate Institute; ${ }^{3}$ Department of Clinical Pathology, Army Institute \\ of Pathology, Phramongkutklao Medical Center, Bangkok, Thailand
}

Received October 28, 2015; Accepted December 4, 2015

DOI: $10.3892 /$ or.2016.4567

\begin{abstract}
Thyroid cancer is the most common human endocrine malignancy with increasing global incidence. Papillary thyroid carcinomas (PTC) and follicular thyroid carcinomas (FTC) are well-differentiated thyroid cancers (WDTC) accounting for $95 \%$ of all thyroid cancer cases, with survival rates of almost $100 \%$ when diagnosed early. Since PTC and FTC have different modes of metastasis, they require different treatment strategies. Standard diagnosis by fine needle aspiration with cytopathological examination can be inaccurate in approximately $10-30 \%$ of all cases and difficult to definitively classify as WDTC. Currently, there is no single or panel of biomarkers available for thyroid cancer diagnosis and classification. This study identified novel biomarkers for thyroid cancer diagnosis and classification using proteomics, which may be translated into a biomarker panel for clinical application. Two-dimensional SDS-PAGE and mass spectrometry were used to identify potential biomarkers in papillary and follicular thyroid carcinoma cell lines, and the biomarkers were validated in five PTC and five FTC tissues, with their adjacent normal tissues from Thai patients. Eight biomarkers could distinguish PTC from normal tissues, namely enolase 1, triose phosphate isomerase, cathepsin D, annexin A2, cofilin 1, proliferating cell nuclear antigen (PCNA), copine 1 and heat shock protein $27 \mathrm{kDa}$ (HSP27). These biomarkers can also discriminate FTC from normal tissues, except for annexin A2. On the contrary, annexin A2, cofilin 1, PCNA and HSP27 can be used to classify the types of WDTC. These findings have potential for use as a novel multi-marker panel for more accurate diagnosis and classification to better guide physicians on thyroid cancer treatment. Moreover, our results suggest the
\end{abstract}

Correspondence to: Dr Nilubol Paricharttanakul, Laboratory of Biochemistry, Chulabhorn Research Institute, 54 Kamphaeng Phet 6, Laksi, Bangkok 10210, Thailand

E-mail: nilubol@cri.or.th

Key words: thyroid carcinoma, proteomics, biomarker, diagnosis, classification involvement of proteins in cell growth and proliferation, and the p53 pathway in the carcinogenesis of WDTC, which may lead to targeted therapy for thyroid cancer.

\section{Introduction}

Thyroid cancer is the most prevalent endocrine malignancy and the eighth most common cancer in females. Presently, thyroid cancer incidence has continuously increased worldwide $(1,2)$. Moreover, the American Cancer Society has reported that the incidence of thyroid cancer is increasing most rapidly compared to other cancers (3). Papillary thyroid carcinomas (PTC) and follicular thyroid carcinomas (FTC) account for $95 \%$ of all thyroid cancer cases. They are clinically classified as well-differentiated thyroid carcinomas (WDTC) due to their biological behavior resembling normal follicular cells and good responsiveness to surgery and radioiodine therapy $(4,5)$. However, PTC and FTC are usually curable when discovered at early stages, but survival rates may be reduced from $100 \%$ in stages I and II to 50\% at stage IV (6). In addition, pathological divergences, such as patterns of metastasis, of PTC and FTC also have significant impact on cancer aggressiveness and treatment. PTC usually invades neighboring tissues and occasionally metastasizes to regional lymph nodes, whereas FTC often metastasizes to bone and lung. Thus the general treatment for WDTC, thyroidectomy with radioiodine therapy, may have different consequences for PTC and FTC (5). Prophylactic lymph node and central neck dissection is an example of different thyroid cancer management between PTC and FTC. Several studies showing that prophylactic lymph node and central neck dissection in PTC potentially decreases cancer recurrence, revealing microscopic lymph node metastases undetectable by other techniques and increasing diseasespecific survival. In contrast, dissections are not recommended for most FTC, except in malignant lymph node cases $(7,8)$. Therefore, FTC is considered to be more aggressive than PTC. For these reasons, early detection and classification of thyroid cancer is necessary for optimal treatment.

Neck ultrasound, laryngeal exam, thyroid function blood test, chest X-ray, thyroid scan with low-dose radioactive iodine and fine needle aspiration (FNA) biopsy are available techniques for thyroid cancer diagnosis. FNA with cytopathological 
examination is the most effective technique for thyroid cancer diagnosis and classification. However, approximately 10-30\% of FNA results are misdiagnosed due to inadequate aspirated materials, cytodiagnostic errors, missed sampling and nodule compositions $(9,10)$. In addition, detections of specific genetic alterations from FNA and thyroid cancer tissue samples have been studied for decades and some biomarkers have been identified (e.g. BRAF and RAS mutation). However, determination of disease status based on genomic analysis and gene expression data alone are limited due to translational modifications such as mRNA splicing and post-translational modifications. Thus, proteomics is an option to identify potential biomarkers for cancer diagnosis that can fulfill the discordance of genetic biomarkers and improve the effectiveness of thyroid cancer diagnosis $(4,5,11,12)$. Several studies, including those from our group, have revealed potential protein biomarkers from thyroid tissues, e.g., galectin 3, cathepsin B, cytokeratin 19 (CK19) and e-cadherin (13-17). Unfortunately, these biomarkers do not have enough specificity to be used clinically. Galectin 3 is one of the most studied thyroid cancer biomarkers. We have shown galectin 3 to have higher expression in PTC, compared to FTC and benign tissues (15). However, it is overexpressed in other cancers such as breast cancer, lung cancer, esophageal cancer, and laryngeal cancer, making it difficult to discriminate between thyroid cancer and other cancers $(15,18,19)$. In addition, galectin 3 is also expressed by macrophages and activated endothelial cells, which can interfere with diagnosis (18).

Current interest focuses on using a panel of multiple biomarkers for diagnosis, which should be more reliable than using single biomarkers. Several studies on thyroid cancer have revealed that panel biomarkers have higher specificities than a single marker alone $(17,20,21)$. The specificity of using a panel of three biomarkers for detection of thyroid cancer, namely galectin 3, CK19 and monoclonal antibody against microvillus surface antigen (HBME), increased by 18,14 and $4 \%$, respectively, when compared to those of galectin $3, \mathrm{CK} 19$ and HBME alone (21). However, there is still a need for classification of thyroid cancer for appropriate treatment, so it would be beneficial to have a panel of biomarkers for detection, as well as classification of thyroid carcinomas. In this study, we aimed to identify novel biomarkers for thyroid cancer diagnosis and classification using proteomics for improved thyroid cancer management.

\section{Materials and methods}

Cell culture. Human papillary thyroid carcinoma (B-CPAP) cell line and human follicular thyroid carcinoma (FTC-133) cell line were kindly provided by Professor Johan Lillehaug, University of Bergen, Norway. B-CPAP cells were cultured in RPMI medium supplemented with $10 \%$ heat-inactivated fetal bovine serum (FBS) and 1\% penicillin-streptomycin-amphotericin-B solution. FTC-133 cells were cultured in 1:1 mixture of DMEM: Ham's F-12 media supplemented with $10 \%$ heatinactivated FBS, $1 \%$ penicillin-streptomycin-amphotericin-B solution and $1 \% 200 \mathrm{mM}$ L-glutamine. The cells were incubated at $37^{\circ} \mathrm{C}$ in $5 \% \mathrm{CO}_{2}$.

Human specimens. Five human papillary carcinoma (PTC) tissues and their adjacent normal tissues, as well as five human follicular carcinoma (FTC) tissues and their adjacent normal tissues were obtained from Phramongkutklao Medical Center, Bangkok, Thailand after approval of the research protocol (S012H) by the Institutional Review Board of the Royal Thai Army Medical Department, Thailand. Histopathology confirmed diagnoses of the tissues. Tissues were stored at $-80^{\circ} \mathrm{C}$ until ready to be processed.

Protein extraction. Cells were harvested from culture flasks in $0.25 \mathrm{M}$ sucrose with protease inhibitor cocktail (ratio of 500:1) (Sigma-Aldrich P8340, St. Louis, MO, USA) using cell scraper and then centrifuged at $500 \mathrm{x} \mathrm{g}$ at $4^{\circ} \mathrm{C}$ for $10 \mathrm{~min}$. The cell pellets were lysed using lysis buffer containing $9 \mathrm{M}$ urea, 2\% CHAPS, 2\% DTT, 5\% ampholine (pH 3-10) and 500:1 protease inhibitor cocktail for $1 \mathrm{~h}$ at room temperature, sonicated and then centrifuged at $12,000 \mathrm{x} \mathrm{g}$ at $4^{\circ} \mathrm{C}$ for $10 \mathrm{~min}$. Bradford assay was used to determine protein concentration in supernatants.

Invasion and migration assays. Cell invasion and migration assays were performed using Transwell chambers (pore size $8.0 \mu \mathrm{m}$, Corning). For invasion assay, the upper chambers were coated with Matrigel (30 $\mu \mathrm{g}$ protein/well). Cells $\left(10^{4}\right)$ were seeded onto the upper chamber and $600 \mu \mathrm{l}$ medium containing $10 \%$ FBS was added to the lower chamber, and incubated at $37^{\circ} \mathrm{C}$ for $24 \mathrm{~h}$ with $5 \% \mathrm{CO}_{2}$. Non-migrating or non-invading cells on the upper chambers were removed using cotton swabs. The migrating or invading cells on the upper chamber were fixed in $25 \%$ methanol for $15 \mathrm{~min}$ and then stained with $0.5 \%$ crystal violet for $15 \mathrm{~min}$. Excess dye was rinsed with RO water for $30 \mathrm{sec}$, swabbed and then cells dried at $70^{\circ} \mathrm{C}$ overnight. Photographs were taken and then dye was eluted using HCl-methanol solution (1:9 ratio) for $5 \mathrm{~min}$. Absorbance was measured at $550 \mathrm{~nm}$.

Two-dimensional SDS-PAGE and image analysis. Immobiline $^{\mathrm{TM}}$ Drystrips ( $7 \mathrm{~cm}, \mathrm{pH}$ 3-10 nonlinear) were rehydrated for $16 \mathrm{~h}$ with $150 \mu \mathrm{g}$ protein samples. The first dimension was performed at 7,000 Vh by using Ettan IPGphor 3 (GE Healthcare Co.). For the second dimension, strips were incubated with equilibration buffer containing 1,4-dithioerythritol (DTT) for $10 \mathrm{~min}$ followed by incubation with equilibration buffer containing iodoacetamide (IAA) for $10 \mathrm{~min}$. Proteins were separated in $12.5 \%$ SDS-PAGE gel at $10 \mathrm{~mA} /$ gel using PowerPac Basic ${ }^{\mathrm{TM}}$ (Bio-Rad) apparatus. Gels were stained with Coomassie blue R-250 and then scanned by using Labscan 5.0 software. Protein spots were analyzed by ImageMaster 2D Platinum 7.0 program and differential protein expression between the cell lines was measured as percent volume. Protein spots with expression $>1.3$-fold were selected for identification.

In-gel digestion. Selected spots were excised and then destained with $50 \%$ acetonitrile $(\mathrm{ACN})$ in $0.1 \mathrm{M} \mathrm{NH}_{4} \mathrm{HCO}_{3}$ followed by reduction and alkylation using $10 \mathrm{mM}$ DTT for $45 \mathrm{~min}$ at $60^{\circ} \mathrm{C}$ and $100 \mathrm{mM}$ IAA at room temperature for $30 \mathrm{~min}$ in the dark, respectively. Finally, dried gels were digested with $0.01 \mu \mathrm{g}$ of trypsin (Promega Co.) in digestion buffer at $37^{\circ} \mathrm{C}$ overnight and then supernatants were collected for protein identification. 
Protein identification using $L C-M S / M S$. Trypsin-digested peptides were identified by LC-MS/MS. In brief, $\mathrm{C}_{18}$ EASY$\mathrm{nLC}^{\mathrm{TM}}$ column (Thermo Scientific, Rockford, IL, USA) was used to concentrate and desalt digested peptides. Peptides were eluted off the column by using solutions A and B which were composed of $0.1 \%$ formic acid in $97 \%$ water with $3 \%$ $\mathrm{ACN}$ and $0.1 \%$ formic in $97 \% \mathrm{ACN}$, respectively, and injected into nano ESI MS/MS (Amazon speed ETD, Bruker Co.) to generate MS/MS spectra. Parent mass peaks within the range of $50-3000 \mathrm{~m} / \mathrm{z}$ were selected for MS/MS analysis and the MS/MS spectra were processed using Bruker Compass 1.4 software. Mascot search engine (www.matrixscience.com) was used to identify proteins with the following parameters: NCBI database in Homo sapiens taxonomy, enzyme used: trypsin, missed cleavage allowed: one, fixed modification: carbamidomethyl (C) and variable modification: phospho (ST) and phospho $(\mathrm{Y})$, peptide tolerance: $1.2, \mathrm{MS} / \mathrm{MS}$ mass tolerance: $0.6 \mathrm{kDa}$, and peptide charges: $1+, 2+$ and $3+$. Identified proteins with consistent molecular weight and $\mathrm{pI}$ with their positions in the gels, Mascot score $>25$ and $\mathrm{p} \leq 0.05$ were considered as candidate biomarkers.

Western blot analysis. Proteins were separated on $12.5 \%$ SDS-PAGE and electro-transferred onto PVDF membranes. Membranes were blocked with 5\% bovine serum albumin (BSA) at $4^{\circ} \mathrm{C}$, overnight and then probed with antibody against Annexin A1 (1:1000, Chemicon International Inc.), annexin A2 (1:1000, Abcam Inc.), heterogeneous nuclear ribonucleoprotein $\mathrm{K}$ or hnRNP K (1:500, Cell signaling

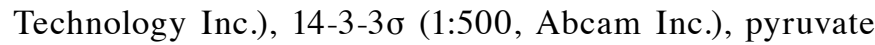
kinase (1:1000, Santa Cruz Biotech Inc.), enolase 1 (1:1000, Abcam Inc.), glyceraldehyde-3-phosphate dehydrogenase or GAPDH (1:1000, Abcam Inc.), triose phosphate isomerase or TPI (1:2000, Abcam Inc.), copine 1 (1:2000, Abcam Inc.), cathepsin D (1:1000, Abcam Inc.), cofilin 1 (1:500, Abcam Inc.), heat shock $27 \mathrm{kDa}$ protein or HSP27 (1:10000, Abcam Inc.), $\beta$-actin (1:10000, Cell signaling Technology Inc.), proliferating cell nuclear antigen or PCNA (1:5000, Abcam Inc.) and tubulin as loading control (1:5000, Cell Signaling Technology Inc.) for $2 \mathrm{~h}$ at room temperature. Then, membranes were washed with TBS/T buffer (TBS, $0.1 \%$ Tween-20) and then blocked with $5 \%$ skim milk for $30 \mathrm{~min}$. The membranes were incubated with the corresponding secondary antibodies for $45 \mathrm{~min}$ and washed again. Finally, membranes were incubated with ECL reagent for $5 \mathrm{~min}$ and exposed to film. Labscan 5.0 instrument was used to scan exposed film and band intensities were measured using ImageQuan TL software (GE Healthcare Co.).

Pathway analysis. The network most significantly influenced when comparing PTC and FTC cell lines was predicted by using Ingenuity Pathway Analysis (IPA ${ }^{\circledR}$, Qiagen Redwood City, CA, USA; www.qiagen.com/ingenuity). Accession numbers and fold-changes of proteins were provided in a dataset. Criteria input in the software are as follows: Reference set, Ingenuity Knowledge Base (genes only); Relationship to consider, Direct and Indirect relationships; Networks, interaction; Data source, all; Confidence, Experimentally Observed; Species, Human; Tissues and cell lines, Other cell line; and Mutation, all.
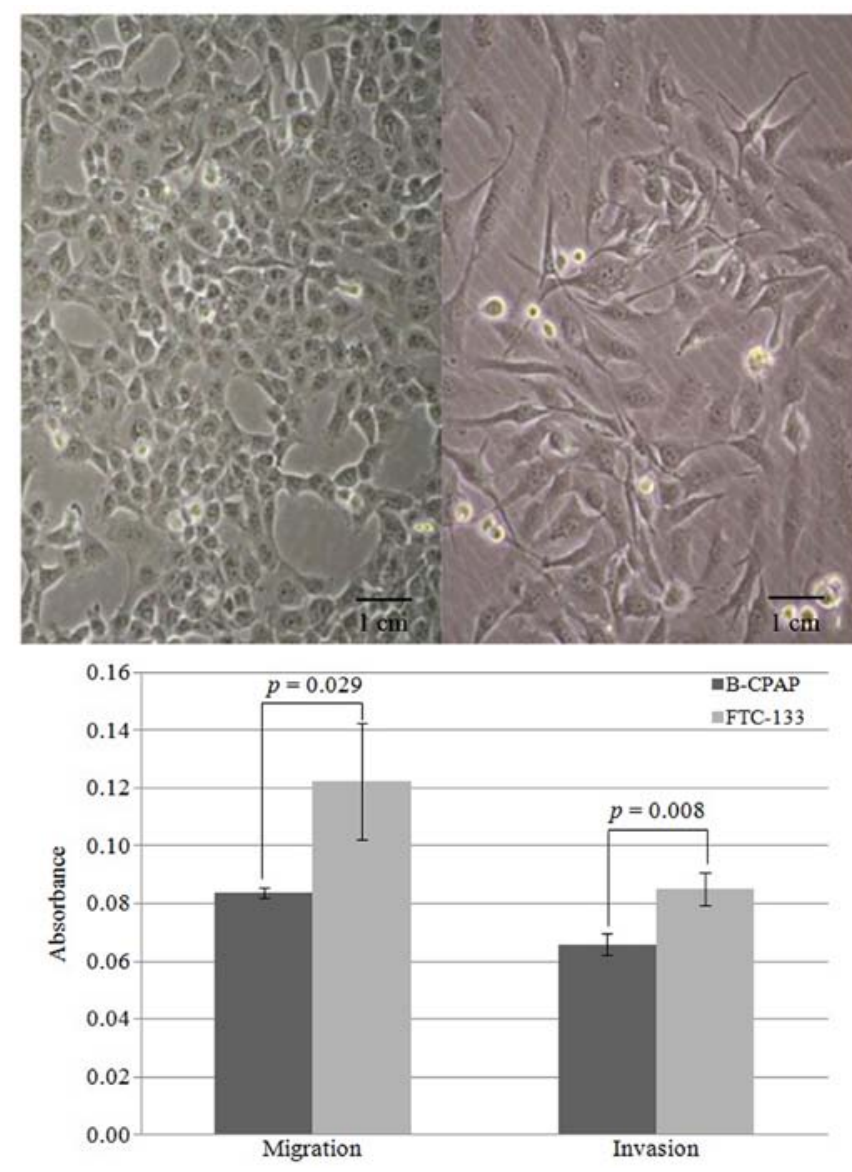

Figure 1. Characteristics of B-CPAP and FTC-133 cell lines. Cell morphologies of B-CPAP (left) and FTC-133 (right) under phase contrast microscope at x100 magnification are shown on the upper panel. Invasiveness of B-CPAP and FTC-133 cells, as determined by Transwell migration and invasion assays, are shown in the bottom panel. The results showed that FTC-133 is significantly more invasive than B-CPAP cells.

Biomarker validation. Proteins from human tissues were extracted using a hand homogenizer. In brief, $20 \mathrm{mg}$ of tissue was lysed by $150 \mu 1$ of RIPA buffer $(150 \mathrm{mM} \mathrm{NaCl}, 1.0 \%$ Triton X-100, 0.5\% sodium deoxycholate, $0.1 \%$ SDS, $50 \mathrm{mM}$ Tris pH 8.0 and $1 \mathrm{mM}$ EDTA) containing protease inhibitor and then homogenized by hand homogenizer and incubated on ice for $1 \mathrm{~h}$. Samples were centrifuged at $12,000 \mathrm{x} g$ at $4^{\circ} \mathrm{C}$ for $10 \mathrm{~min}$ and the supernatants were collected. Protein concentrations in samples were determined by using Bradford assay. Then, protein markers were validated by western blot analysis as previously described.

Statistical analysis. Experimental data are presented as the mean \pm SE. The statistical significances of data between samples were determined using the appropriate statistics, namely ANOVA for spot analysis and unpaired Student's t-test or paired Student's t-test for others. Data were considered significantly different at $p$-values $<0.05$.

\section{Results}

The differential diagnosis of well-differentiated thyroid carcinomas such as papillary thyroid carcinoma and follicular thyroid carcinoma requires skilled pathology examination 
Table I. Identification of selected proteins by LC/MS/MS and Mascot database search.

\begin{tabular}{|c|c|c|c|c|c|c|c|c|c|}
\hline $\begin{array}{l}\text { Spot } \\
\text { ID }\end{array}$ & Accession no. & Protein name & $\mathrm{MW} / \mathrm{pI}$ & Coverage & $\begin{array}{l}\text { Peptide } \\
\text { match }\end{array}$ & $\begin{array}{l}\text { Mascot } \\
\text { score }\end{array}$ & $\begin{array}{l}\text { Fold } \\
\text { change }\end{array}$ & $\mathrm{P}$-value & Function \\
\hline 8 & gil28336 & $\beta$-Actin & $42128 / 5.22$ & 16 & 5 & 260 & 3.1521 & 0.006 & $\begin{array}{l}\text { Structure } \\
\text { protein }\end{array}$ \\
\hline 19 & gil5031635 & Cofilin 1 & $18719 / 8.22$ & 30 & 5 & 216 & 2.255 & 0.002 & $\begin{array}{l}\text { Invasion and } \\
\text { metastasis }\end{array}$ \\
\hline 60 & gil4504517 & $\begin{array}{l}\text { Heat shock } 27 \mathrm{kDa} \\
\text { protein }\end{array}$ & $22826 / 5.98$ & 36 & 8 & 358 & 3.9332 & 0.000 & Stress response \\
\hline 68 & gil4502101 & Annexin A1 & $38918 / 6.57$ & 4 & 2 & 76 & 1.6415 & 0.022 & $\begin{array}{l}\text { Cell growth and } \\
\text { proliferation }\end{array}$ \\
\hline 69 & gil4507645 & $\begin{array}{l}\text { Triosephosphate } \\
\text { isomerase (TPI) }\end{array}$ & $26938 / 6.45$ & 55 & 12 & 548 & 1.3202 & 0.049 & Glycolysis \\
\hline 95 & gil4503143 & Cathepsin D & $45037 / 6.10$ & 6 & 3 & 119 & 2.4007 & 0.000 & $\begin{array}{l}\text { Invasion and } \\
\text { metastasis }\end{array}$ \\
\hline 115 & gil31645 & $\begin{array}{l}\text { Glyceraldehyde-3-phosphate } \\
\text { dehydrogenase (GAPDH) }\end{array}$ & $36202 / 8.26$ & 30 & 9 & 311 & 2.2176 & 0.001 & Glycolysis \\
\hline 130 & gil49456555 & $\begin{array}{l}\text { Proliferating cell nuclear } \\
\text { antigen (PCNA) }\end{array}$ & $29029 / 4.57$ & 32 & 9 & 395 & 1.7506 & 0.005 & $\begin{array}{l}\text { Cell growth and } \\
\text { proliferation }\end{array}$ \\
\hline 195 & gil4503571 & Enolase 1 & $47481 / 7.01$ & 41 & 19 & 657 & 1.6857 & 0.029 & Glycolysis \\
\hline 228 & gil35505 & Pyruvate kinase (PK) & $58411 / 7.58$ & 30 & 17 & 714 & 1.7031 & 0.017 & Glycolysis \\
\hline 359 & gil460789 & $\begin{array}{l}\text { Heterogeneous nuclear } \\
\text { ribonucleoprotein } \mathrm{K} \\
(\mathrm{hnRNPK})\end{array}$ & $51325 / 5.13$ & 5 & 2 & 71 & $\begin{array}{l}\text { Present in } \\
\text { FTC133 }\end{array}$ & 0.000 & $\begin{array}{l}\text { Cell growth and } \\
\text { proliferation }\end{array}$ \\
\hline 381 & gil350610434 & $14-3-3 \sigma$ & $26584 / 4.90$ & 14 & 4 & 150 & $\begin{array}{l}\text { Present in } \\
\text { BCPAP }\end{array}$ & 0.000 & $\begin{array}{l}\text { Anti-apoptosis and } \\
\text { drug resistance }\end{array}$ \\
\hline 386 & gil114794644 & Annexin A2 & $35448 / 8.21$ & 33 & 10 & 470 & $\begin{array}{l}\text { Present in } \\
\text { BCPAP }\end{array}$ & 0.000 & $\begin{array}{l}\text { Invasion and } \\
\text { metastasis }\end{array}$ \\
\hline 419 & gil23397696 & Copine 1 & $59649 / 5.52$ & 11 & 7 & 236 & $\begin{array}{l}\text { Present in } \\
\text { BCPAP }\end{array}$ & 0.000 & Others \\
\hline
\end{tabular}

from fine-needle aspiration of the thyroid nodule. Even though both types of carcinomas are treatable by thyroidectomy and iodine ablation, follicular thyroid carcinoma is considered to be more aggressive and has higher recurrence than papillary thyroid carcinomas (4,22-24). Treatment regimens using molecular-targeted chemotherapy also differ, so it is prudent to distinguish between papillary thyroid carcinoma and follicular thyroid carcinoma (25). Herein, we provide a panel of biomarkers that will not only differentiate between these two well-differentiated thyroid carcinomas but also diagnose normal from cancerous lesions.

Cell line characterization. In order to understand the differences between papillary thyroid carcinoma and follicular thyroid carcinoma, cell lines were characterized. Papillary thyroid carcinoma (B-CPAP) and follicular thyroid carcinoma (FTC-133) cell lines exhibited different morphologies and invasiveness (Fig. 1). B-CPAP cells are epithelial-like whereas FTC-133 cells appear spindle-like (Fig. 1 top panel). The doubling times for B-CPAP and FTC-133 cells are 22.8 \pm 1.5 and $27.9 \pm 1.2 \mathrm{~h}$, respectively. Moreover, FTC-133 cells demon- strated increased migration and invasion compared to B-CPAP cells (Fig. 1 bottom panel), consistent with the clinical observation that follicular thyroid carcinomas are more aggressive than papillary carcinomas.

Biomarker identification using proteomics. Classical proteomics using two-dimensional polyacrylamide gel electrophoresis, followed by trypsin digestion and LC/MS/ MS, were performed to identify the global protein expression differences between B-CPAP and FTC-133 cells. The proteomic patterns showed one hundred and one protein spots differing in expression by $>1.3$-fold, as analyzed using ANOVA and these spots were identified by mass spectrometry (data not shown). Fourteen spots appeared in only B-CPAP cells and 39 spots appeared in only FTC-133 cells. In addition, 45 spots had higher expression in B-CPAP cells and 39 spots had higher expression in FTC-133 cells when compared to one another. For B-CPAP cells, functional classification revealed the predominant role of proteins involved in cell growth and proliferation (24\%), structure (14\%), glycolysis (14\%), anti-apoptosis and drug resistance (12\%), invasion and 


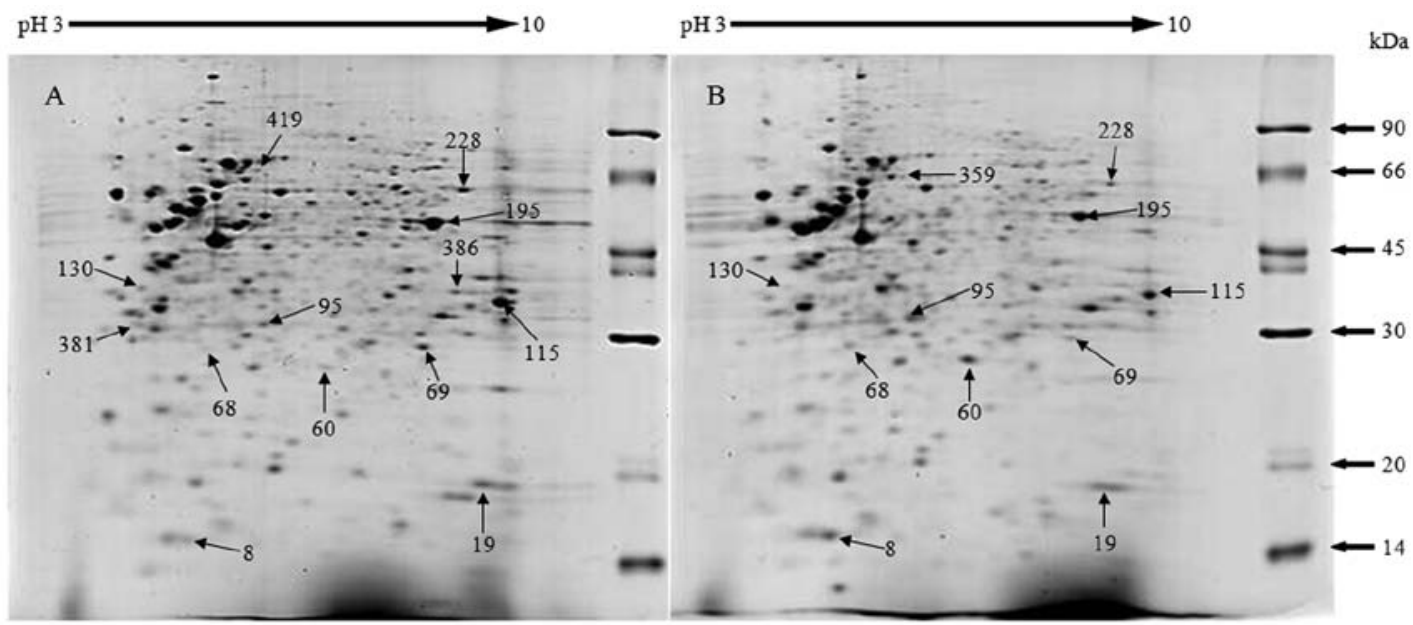

Figure 2. Representative two-dimensional SDS-PAGE of thyroid cancer cell lines. Panels A and B show 2D-gels of B-CPAP cell line and FTC-133 cell line, respectively. Crude lysates $(150 \mu \mathrm{g})$ were separated by using $7 \mathrm{~cm} \mathrm{pH} \mathrm{3-10} \mathrm{nonlinear} \mathrm{strips} \mathrm{and} \mathrm{12.5 \%} \mathrm{SDS-PAGE.} \mathrm{Proteins} \mathrm{were} \mathrm{stained} \mathrm{using} \mathrm{Coomassie} \mathrm{blue}$ R-250. Gels were analyzed using ImageMaster 2D Platinum 7.0 software and ANOVA for statistical analysis. Fourteen selected spots are shown, which were identified by mass spectrometry. The number of the spot corresponds to the number reported in Table I.

\begin{tabular}{|c|c|}
\hline Protein name & B-CPAP \\
\hline$\beta$-Actin & $\square$ \\
\hline Cofilin 1 & 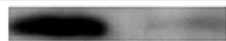 \\
\hline $\begin{array}{l}\text { Heat shock } 27 \\
\text { kDa protein }\end{array}$ & \\
\hline Annexin A1 & $\longrightarrow$ \\
\hline $\begin{array}{l}\text { Triose phosphate } \\
\text { isomerse }\end{array}$ & 2 \\
\hline Cathepsin D & -1 \\
\hline GAPDH & $<$ \\
\hline PCNA & 0 \\
\hline Enolase 1 & 0 \\
\hline Pyruvate kinase & 2 \\
\hline $\mathrm{hnRNPK}$ (65kDa) & 0 \\
\hline hnRNP K (60kDa) & 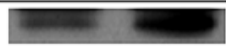 \\
\hline $14-3-3 \sigma$ & 2 \\
\hline Annexin A2 & 2 \\
\hline Copine 1 & 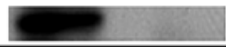 \\
\hline$\alpha$-Tubulin & 04 \\
\hline
\end{tabular}

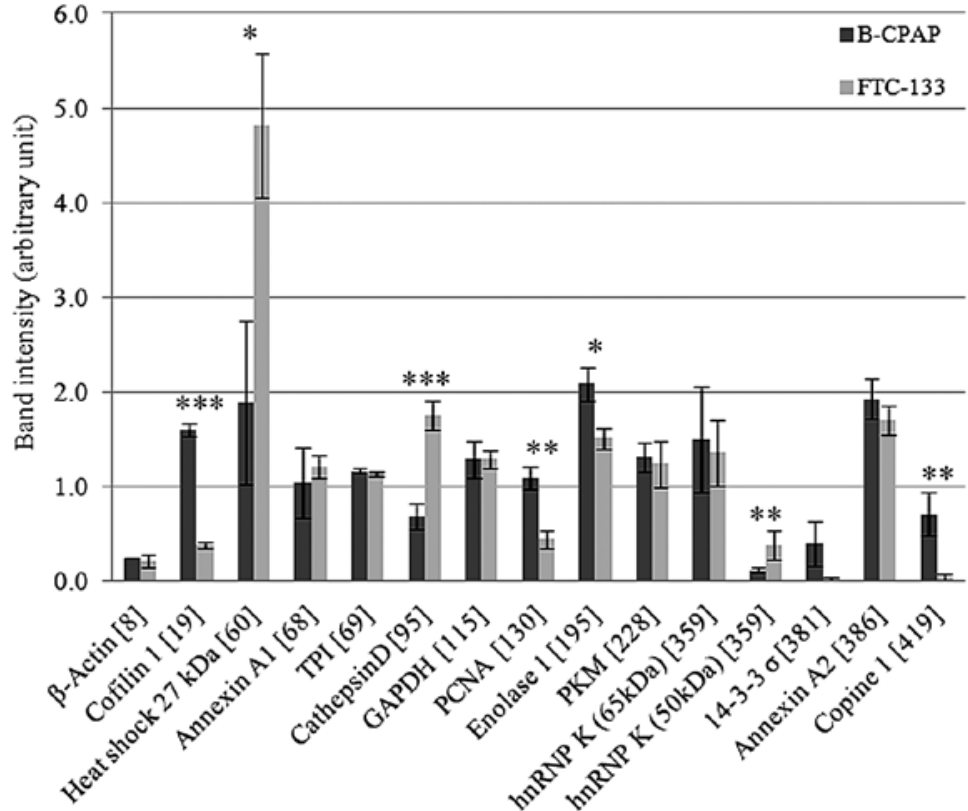

Figure 3. Western blot analyses of selected spots. Western blot bands of selected proteins are shown in the left panel. Band intensities were measured by ImageQuanTL software and normalized using tubulin control, as shown in the right panel. Cofilin 1, HSP27, cathepsin D, enolase 1, PCNA, hnRNP K and copine 1 showed significantly different expression between B-CPAP and FTC-133 cell lines. ${ }^{*} \mathrm{p}<0.05,{ }^{* *} \mathrm{p}<0.005$, and ${ }^{* *} \mathrm{p}<0.001$ using Student t-test.

metastasis $(10 \%)$, stress response $(10 \%)$ and other functions $(16 \%)$. On the other hand, proteins involved in cell growth and proliferation $(30 \%)$, invasion and metastasis (12\%), antiapoptosis and drug resistance $(10 \%)$, stress response $(10 \%)$, glycolysis $(10 \%)$ and other functions $(20 \%)$ were mainly found in FTC-133 cells.

Fourteen spots were selected for further study, representing proteins covering the major functions in the two cell lines, which showed the most significant and/or high fold-changes in expression. For cell growth and proliferation, proliferating cell nuclear antigen (PCNA), heterogeneous nuclear ribonucleoprotein K (hnRNP K) and annexin A1 were selected. For glycolysis, triose phosphate isomerase (TPI), glyceraldehyde3-phosphate dehydrogenase (GAPDH), enolase and pyruvate kinase were selected. For invasion and metastasis, we selected cathepsin D, annexin A2 and cofilin 1. For anti-apoptosis and drug resistance, stress response, structure, and other functions, 14-3-3 $\sigma$, heat shock $27 \mathrm{kDa}$ protein (HSP27), $\beta$-actin, and copine 1 were selected, respectively.

Representative gels of lysates of B-CPAP and FTC-133 cells are shown in Fig. 2, with 14 selected spots differing between the two cell lines labeled. The identities of three spots present in only B-CPAP cells, one spot in only FTC-133 cells, six spots that increased in B-CPAP and four spots that increased 


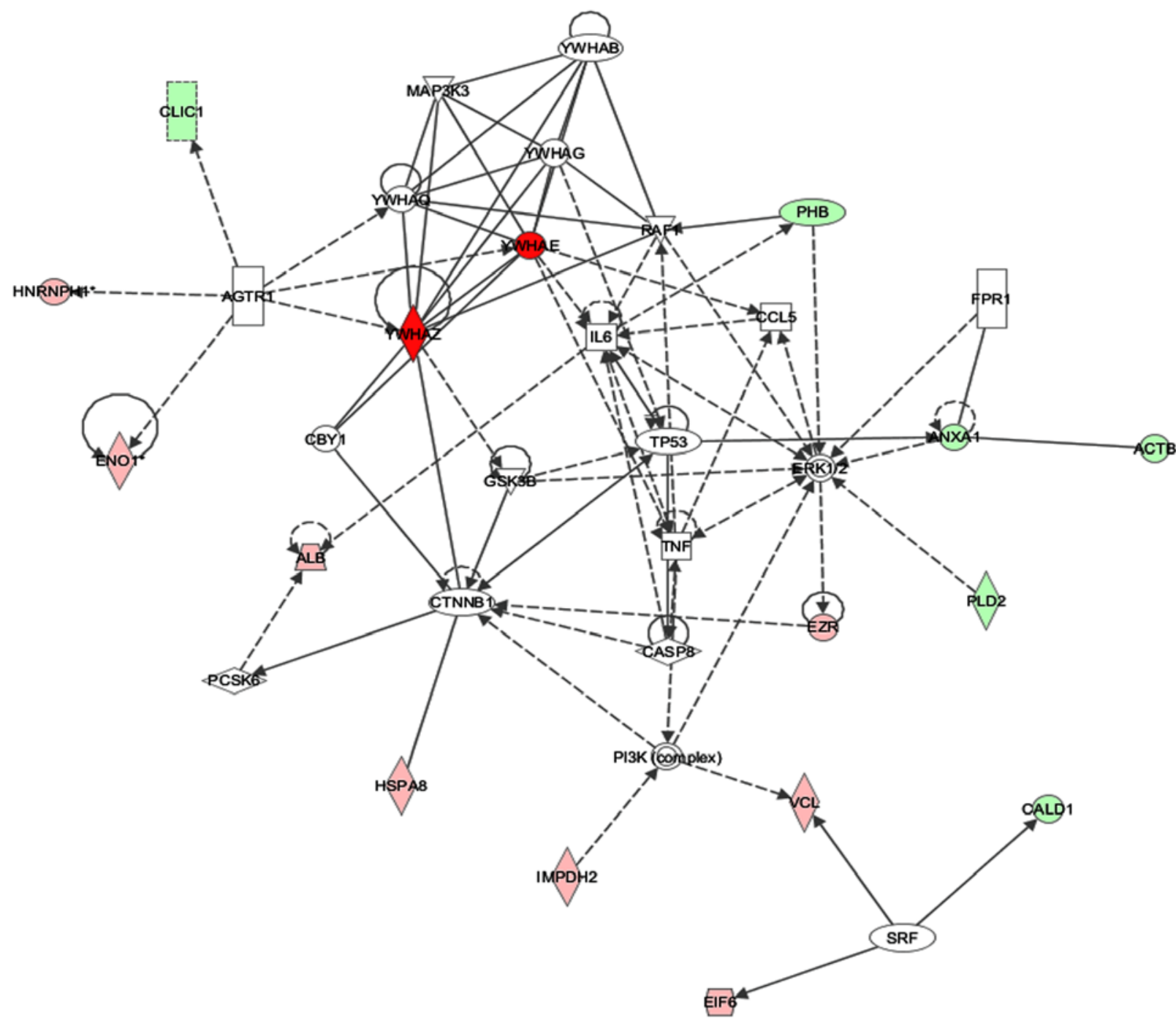

Figure 4. Network analysis using Ingenuity Pathway Analysis (IPA). IPA was used to analyze the biological network of one hundred and one identified proteins, which differed significantly in expression by more than 1.3-fold between B-CPAP and FTC-133 cell lines. IPA revealed the top network containing 16 focus molecules with a score of 23 ; this network is associated with cell death and survival. Proteins shown in green are focus molecules that had decreased expression in B-CPAP cell line, whereas proteins in red are focus molecules with higher expression than in B-CPAP cell line. The intensities of the color correspond to the fold-changes in expression. Solid or dashed lines indicate direct or indirect interactions. No arrows, single arrows or double arrows indicate binding, unidirectional act on, or bidirectional act on, respectively. The following proteins were identified in the network by IPA: ACTB ( $\beta$-actin), ANXA1 (annexin A1), CALD1 (caldesmon 1), CLIC1 (chloride intracellular channel 1), PHB (prohibitin), PLD2 (phospholipase D2), ALB (albumin), EIF6 (eukaryotic translation initiation 6), ENO1 (enolase1), EZR (ezrin), HNRNPH1 (heterogeneous nuclear ribonucleoprotein H1), HSPA8 (heat shock $70 \mathrm{kDa}$ protein 8),

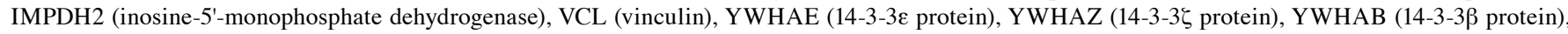

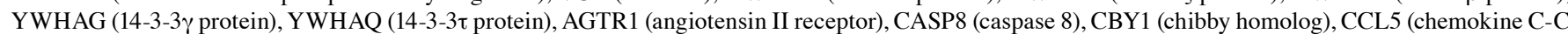
motif ligand 5), CTNNB1 (catenin), ERK1/2 (extracellular signal-regulated kinase), FPR1 (formyl peptide receptor 1), GSK3B (glycogen synthase kinase 3 $\beta$ ), IL6 (interleukin 6), MAP3K3 (mitogen-activated protein kinase 3), PCSK6 (proprotein convertase), PI3K (phosphoinositide 3-kinase), RAF1 (v-Raf1 murine leukemia viral oncogene homolog 1), SRF (serum receptor factor), TNF (tumor necrosis factor), and TP53 (tumor protein p53).

in FTC-133 cells are listed in Table I with their functions. Validations of these identified proteins were performed using immunoblots, as shown in Fig. 3. Cofilin 1, PCNA, enolase 1, and copine 1 showed higher expression in B-CPAP cells, whereas HSP27, cathepsin D and hnRNP K had higher expression in FTC-133 cells with statistical significance. Although the fourteen selected proteins showed differential expression in two-dimensional SDS-PAGE, only seven proteins showed statistically significant differences in expression between the two cell lines by immunoblotting. However, immunoblots were performed using one-dimensional SDS-PAGE and can detect the total expression of the protein of interest based on the epitope recognized by the capture antibody. However, in two-dimensional PAGE, spots differing in isoelectric point and molecular weight are detected. Thus, there could be other isoforms or cleavage forms of the protein with differing expression that would affect the total expression level.

To elucidate the significance of the differentially expressed proteins in cell lines and to predict the relevant biological network involved in the carcinogenesis of papillary thyroid carcinoma and follicular thyroid carcinoma, the complete dataset containing 101 proteins with their fold-changes were entered into Ingenuity Pathway Analysis (IPA). IPA revealed the top network, with a score of 23 , containing 16 focus molecules involved in cell death and survival, tumor morphology and cancer (Fig. 4). The network revolves around 

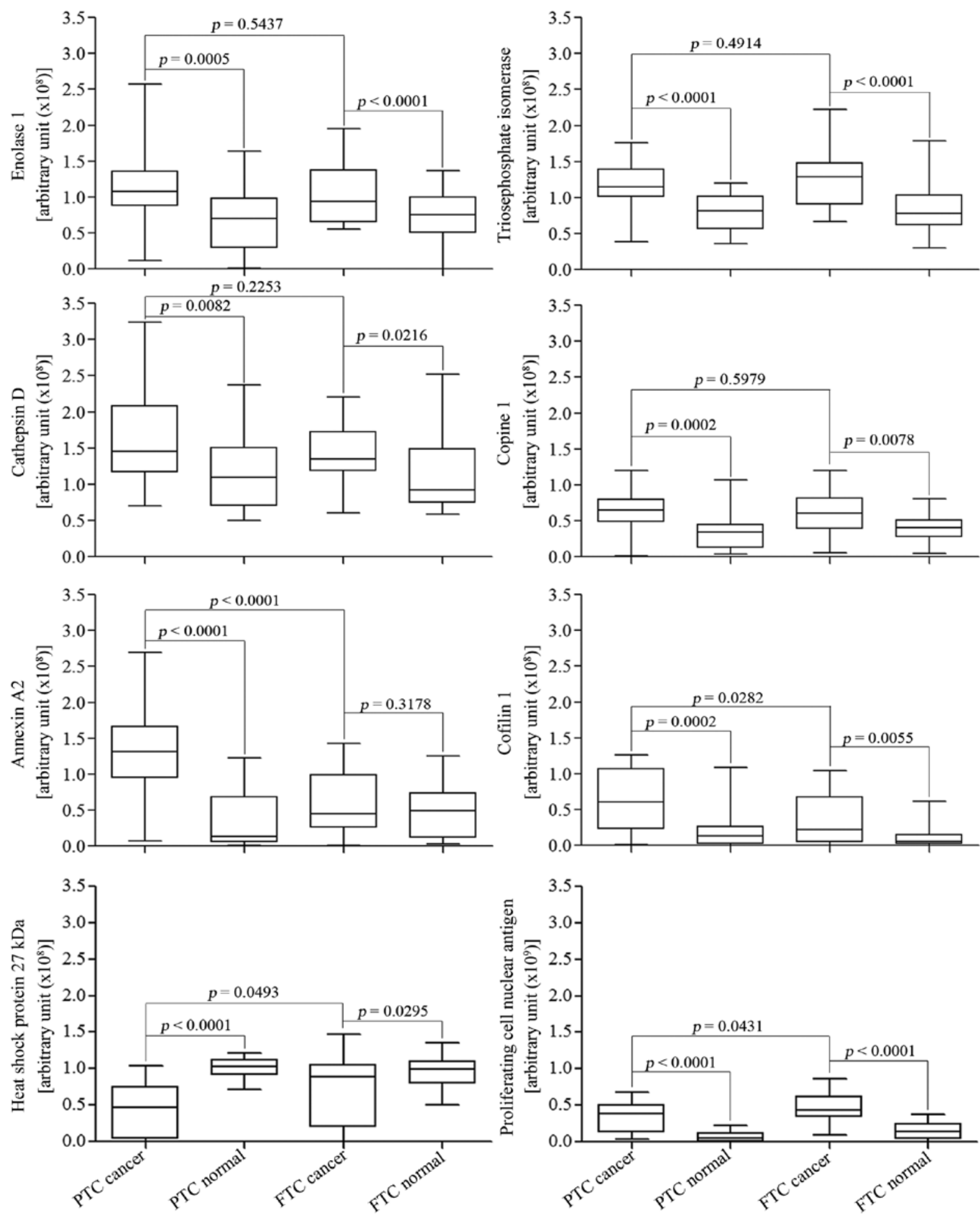

Figure 5. Validation of potential biomarkers for differentiating and classifying PTC, FTC and normal thyroid tissues using western blots. Immunoblots of 5 PTC and 5 FTC tissues with their normal adjacent tissues were performed in triplicate, and band intensities were measured using ImageQuanTL software. Out of the fourteen proteins selected from cell lines, eight proteins showed significant differences in expression when comparing between cancer types, and between cancer and normal tissues, using Student's t-test and paired t-test, respectively. The eight proteins are enolase 1, triose phosphate isomerase (TPI), cathepsin D, cofilin 1, PCNA, copine 1, annexin A2, and heat shock 27 kDa protein (HSP27). Among them, annexin A2 and cofilin 1 are significantly upregulated and HSP27 and PCNA are significantly downregulated in PTC when compared to FTC. All eight can differentiate between PTC and normal tissues, whereas all but cathepsin D $34 \mathrm{kDa}$ and annexin A2 can be used to differentiate between FTC and normal tissues.

interactions with tumor protein $\mathrm{p} 53$ (p53), extracellular signalregulated kinase 1/2 (ERK1/2) and interleukin-6 (IL-6), which are proteins regulating cell growth and proliferation. The expression of p53 is significantly higher in FTC-133 by at least 3-fold than in B-CPAP, but there were no statistically significant differences in IL-6 and ERK1/2 expression, as determined by Western blots (data not shown). Overexpression of p53 in lymph node metastasis of papillary carcinomas has 
Table II. Clinical pathology of human thyroid cancer tissues.

\begin{tabular}{|c|c|c|c|}
\hline Case & Gender & Age & Diagnosis \\
\hline PTC1 & Male & 73 & $\begin{array}{l}\text { Papillary thyroid carcinoma, } \\
\text { both lobes }\end{array}$ \\
\hline PTC2 & Female & 80 & $\begin{array}{l}\text { Papillary thyroid carcinoma, } \\
\text { follicular variant }\end{array}$ \\
\hline PTC3 & Male & 70 & $\begin{array}{l}\text { Papillary thyroid carcinoma } \\
\text { at right robe }\end{array}$ \\
\hline PTC4 & Male & 23 & $\begin{array}{l}\text { Papillary thyroid carcinoma } \\
\text { at left lobe }\end{array}$ \\
\hline PTC5 & Male & 33 & Papillary thyroid carcinoma \\
\hline FTC1 & Male & 51 & $\begin{array}{l}\text { Follicular thyroid carcinoma } \\
\text { at left lobe }\end{array}$ \\
\hline FTC2 & Female & 48 & $\begin{array}{l}\text { Follicular thyroid carcinoma } \\
\text { at left lobe }\end{array}$ \\
\hline FTC3 & Female & 36 & $\begin{array}{l}\text { Follicular thyroid carcinoma } \\
\text { at right lobe }\end{array}$ \\
\hline FTC4 & Female & 51 & $\begin{array}{l}\text { Follicular thyroid carcinoma } \\
\text { at right lobe }\end{array}$ \\
\hline FTC5 & Male & 26 & Follicular thyroid carcinoma \\
\hline
\end{tabular}

been reported using immunohistochemistry, suggesting that p53 is associated with cancer aggressiveness (26). This is consistent with our observations that higher overexpression of p53 is found in the more invasive FTC-133 cells rather than in B-CPAP cells, from both pathway analysis validation and invasion assay. Thus, IPA revealed p53 to be a potential marker with clinical relevance to determine aggressiveness of thyroid cancers.

Biomarker validation. In order to assess the potential use of the fourteen identified proteins from our proteomic study as biomarkers, the expression levels of these proteins were evaluated in human thyroid cancer tissues and their adjacent normal tissues. Table II lists clinical pathology information of five PTC and five FTC tissues from surgical dissection. Western blot analysis revealed seven proteins, namely enolase 1, TPI, cathepsin D, copine 1, annexin A2, PCNA and cofilin 1, to be significantly increased in cancerous tissues, whereas HSP27 showed decreased expression in cancerous tissues when compared to their normal adjacent tissues. All eight proteins can distinguish between PTC and normal tissues. However, all proteins, except for annexin A2, can distinguish between FTC and normal tissues. Four proteins have the potential to be used as biomarkers for classifying thyroid cancer, since annexin A2 and cofilin 1 were significantly upregulated, and HSP27 and PCNA were significantly downregulated in PTC tissues when compared to FTC tissues (Fig. 5).

\section{Discussion}

In this study, we identified novel potential biomarkers for thyroid cancer diagnosis and classification. Novel options for thyroid cancer diagnosis are necessary because of the $30 \%$ inconclusive diagnosis from fine needle aspirated biopsies and the increasing incidence of thyroid incidentalomas (10). Moreover, there is increasing evidence on the impact of prophylactic lymph node and central neck dissection on PTC, revealing potential benefits of classifying thyroid cancer in the disease management $(7,8)$. It is widely accepted that biomarkers are useful tools for detecting cancer, monitoring disease progression and possibly identifying novel therapeutic targets. Although thyroid cancer biomarkers have been studied for several decades, only few biomarkers for thyroid cancer classification are available, such as $B R A F$ mutation and $R E T / P T C$ rearrangement in $\mathrm{PTC}$, and $R A S$ mutation and $P P A R \gamma$ rearrangement in FTC $(13,27)$. However, it is difficult to determine point mutations in genes or gene rearrangements, and these genomic biomarkers may not be correlated with actual clinical pathology (13). Thus, using protein biomarkers is a better option for thyroid cancer diagnosis and classification.

In this study, proteomic analysis was performed on thyroid cancer cell lines, B-CPAP and FTC-133, to represent papillary and follicular carcinomas, respectively. Out of one hundred and one proteins with differential expression, 14 potential biomarkers were identified from the cell line study. Validation of these proteins on thyroid cancer tissues from Thai patients revealed that expression of enolase 1, TPI, cathepsin D, copine 1, annexin A2, cofilin 1, PCNA and HSP27 are significantly different between normal and cancer tissues. Moreover, four proteins namely annexin A2, cofilin 1, PCNA and HSP27 showed significantly different expression between PTC and FTC tissues.

Among the eight newly discovered biomarkers from our study, two are glycolytic enzymes, namely enolase 1 and triose phosphate isomerase, which are overexpressed in thyroid cancer. The overexpression of glycolytic enzymes supports anaerobic proliferation (Warburg effect) and this phenomenon has been widely accepted as a major source of ATP production in cancer cells $(28,29)$. TPI is a glycolytic enzyme that converts dihydroxyacetone phosphate to glyceraldehyde3 -phosphate (28). Some studies have reported that TPI has potential as a biomarker for lung squamous cell carcinoma and pancreatic cancer $(30,31)$. Enolase 1 commonly exists in the cytoplasm of cells and acts as a glycolytic enzyme that converts phospho-D-glycerate to phosphoenolpyruvate (28). The expression of enolase 1 is upregulated in various types of cancers, e.g., breast and cervical cancers (29). In contrast, the expression of enolase 1 is downregulated in non-small cell lung cancer, and is associated with poor survival rates. Enolase 1 may be alternatively translated to maltose binding protein 1 (MBP1) and then acts as a MYC inhibitor, inducing cell death and suppressing cell growth (32). Enolase 1 is also associated with cancer invasion and metastasis by acting as a plasminogen-binding receptor. When enolase 1 integrates into the cell membrane, it promotes plasmin activity leading to cancer cell invasion and metastasis by degrading the extracellular matrix (33).

Cathepsin D is a member of the cathepsin protease family found in lysosomes and phagosomes that is activated at acidic $\mathrm{pH}$ (34). Members of the family, namely cathepsins $\mathrm{B}, \mathrm{D}$ and $\mathrm{L}$, have been reported to cleave thyroglobulin in the thyroid resulting in the release of thyroid hormones, 
triiodothyronine and thyroxine (16,35). Cathepsins B and L are cysteine proteases that are more effective in proteolytic cleavage of thyroglobulin in thyroid lysosomes but are less stable than cathepsin D, an aspartic protease (35). Cathepsin D is overexpressed in breast cancer and proposed to be involved in cancer metastasis, cell proliferation and tumor angiogenesis, and fibroblast proliferation, thus being a marker for aggressiveness of breast cancer (34). Kraimps et al reported the overexpression of cathepsin D in thyroid neoplastic tissues and proposed cathepsin $\mathrm{D}$ to be a prognostic marker for poor survival of advanced stage thyroid cancer, consistent with our results that cathepsin D expression was upregulated in thyroid carcinomas compared to normal tissues (36). Previously, our group demonstrated cathepsin B overexpression in malignant thyroid tissues when compared to follicular adenomas $(15,16)$. However, when comparing the two cell lines, cathepsin B did not show differential expression by at least 1.3 -fold and was thus not selected for the tissue validation in this study. Using immunoblotting, we did detect the presence of the active form and heavy chain of cathepsin B, including their isoforms, at different expression levels between the two cell lines, without affecting the overall protein expression (data not shown). This suggests the involvement of post-translational modifications in cathepsin B and we plan to investigate the role of these modifications in thyroid carcinogenesis.

Annexin A2 is a calcium-dependent, anionic phospholipid binding protein that exists in monomeric and heterotetrameric forms. The monomeric annexin A2 is located in the cytoplasm, whereas the heterotetramer is located in the plasma membrane. However, annexin A2 is more strongly expressed in the cell membrane rather than the cytoplasm $(37,38)$. The overexpression of annexin A2 has been found in several cancers including gastric carcinoma, breast cancer, colorectal cancer, pancreatic cancer, prostate cancer, high-grade gliomas and kidney cancer $(37,38)$. Moreover, the overexpression of annexin $\mathrm{A} 2$ has been shown to affect biological processes such as proliferation, apoptosis, invasion and metastasis. Membrane annexin A2 acts as a receptor or a binding protein for several types of proteases, e.g., cathepsin B, plasminogen and tissue plasminogen activator, and extracellular matrix proteins. Therefore, the expression of annexin A2 on the cell membrane is associated with cancer cell invasion, lymph node metastasis and poor prognosis (37-39).

Cofilin 1 is a small ubiquitous protein $(\sim 19 \mathrm{kDa})$ that regulates actin polymerization and depolymerization through different phosphorylation patterns. Actin dynamics is related to cell motility, which is an essential mechanism for cancer invasion and metastasis $(40,41)$. The overexpression of cofilin 1 has been reported in various cancers, e.g., ovarian cancer and oral squamous cellular carcinoma (OSCC) (40-42). In papillary thyroid carcinomas, the overexpression of cofilin 1 has been reported in fine needle biopsy samples (14). Moreover, high phosphorylation levels of cofilin 1 have been reported in melanoma, and breast and prostate cancer. The upregulation of both expression and phosphorylation of cofilin 1 is associated with cancer invasion, metastasis and poor prognosis (40-42).

Proliferating cell nuclear antigen (PCNA) or cyclin is a well-known cell cycle marker that promotes DNA replication by acting as a cofactor for DNA polymerase $\delta$, a major eukaryotic DNA polymerase (43). The expression of PCNA in non-proliferating cells is usually low, but it is elevated in cells during S-phase or when cells have DNA damage (43). Therefore, PCNA is overexpressed in many cancers, such as thyroid cancer, breast cancer, pancreatic cancer and astrocytomas $(43,44)$. PCNA has been reported to be involved in the molecular carcinogenesis of papillary thyroid carcinoma and the overexpression of PCNA was correlated with increased malignancy of thyroid cancers $(44,45)$. Our results, showing that PCNA expression is higher in the more invasive FTC than in PTC, are consistent with these findings.

Copine 1 is a member of a novel family of ubiquitous calcium dependent, membrane-binding proteins. These proteins are highly conserved and widely expressed in eukaryotes. The biological function of copine 1 is poorly understood $(46,47)$. However, several studies have reported that copine 1 has more than 20 target binding protein partners, such as tyrosine/threonine kinase1/extracellular signal-regulated necrosis factor- $\alpha$ (TNF- $\alpha$ ) and nuclear factor $\kappa$-light-chain-enhancer of activated B cells (NF-kB) $(46,48)$. Therefore, copine 1 may be involved in various biological processes, e.g., inflammation, apoptosis, autophagy, growth control, mitosis, gene transcription, exocytosis and cytoskeleton organization (46-48). This is the first report to identify the upregulation of copine 1 expression in thyroid cancer, which warrants further studies.

Heat shock protein $27 \mathrm{kDa}$ (HSP27) is a member of the heat shock protein family. The heat shock protein family is a group of cellular protective molecules that is activated under stress conditions such as heat and irradiation. HSP27 is inducible and is an ATP-independent chaperone activated when in the oligomeric form. Oligomerization of HSP27 is promoted by several stresses such as heat and cell-cell contact $(49,50)$. Clinically, HSP27 is overexpressed in many cancers such as breast cancer, bladder cancer, ovarian cancer, osteosarcoma, endometrial cancer and leukemia $(50,51)$. On the contrary, our group has reported HSP27 downregulation in malignant thyroid tumors as compared to benign tumors, consistent with our current findings that HSP27 exhibited decreases in expression in PTC and FTC compared to their adjacent normal tissues (16). Of note, HSP27 restrains cellular apoptosis and necrosis, resulting in the promotion of cancer cell survival and resistance to chemotherapy (50). Anoikis resistance is a hallmark of cancer metastasis that prevents cancer cell death under detachment (52). Approximately $20 \%$ of FTC cases usually metastasize to the bone and lung through the blood circulatory system, i.e., FTC is resistant to anoikis $(4,23)$. However, the mechanism of anoikis resistance in thyroid cancer, especially in FTC, remains to be elucidated. We observed the overexpression of HSP27 in FTC rather than in PTC, suggesting that HSP27 may be involved in the mechanism of anoikis resistance in FTC, thus supporting the idea that FTC is more invasive than PTC.

Our results showed that four out of eight potential biomarkers (enolase 1, annexin A2, cofilin 1 and cathepsin D) are associated with invasion and metastasis in various cancers. Therefore, we hypothesize that the mechanism of thyroid cancer invasion may be initiated by overexpression of annexin A2 and enolase 1. These two proteins can intercalate into the plasma membrane of cancer cells, act as cathepsin D or plasminogen receptor and then promote the degradation of extracellular matrix to allow for translocation of cancer cells. 
Consequently, cofilin 1 induces actin dynamics that initiates cancer cell motility and then promotes invasion and metastasis. Moreover, annexin A2 and cofilin 1 are significantly upregulated in PTC compared to FTC, thus, these two proteins may be involved in different modes of metastasis in PTC and FTC. Future studies on the role of annexin A2 and cofilin 1 in metastasis may improve our knowledge on the mechanisms involved and reveal specific molecular targets for the treatment of PTC.

In conclusion, we have discovered eight potential biomarkers for thyroid cancer diagnosis and four possible biomarkers that differentiate between PTC and FTC. The eight biomarkers are enolase $1, \mathrm{TPI}$, cathepsin D, cofilin 1 , copine 1, annexin A2, PCNA and HSP27. All eight can be used to differentiate between PTC and normal tissues, while enolase 1, TPI, cathepsin D, cofilin 1, copine 1, PCNA and HSP27 can be used to differentiate between FTC and normal tissues. For classification of well-differentiated thyroid carcinomas, annexin A2, cofilin 1, PCNA and HSP27 can be used. Moreover, p53 may be an additional biomarker to indicate the aggressiveness of thyroid carcinomas.

We hope that a multi-marker panel using these potential biomarkers will provide for better diagnosis for early detection and classification of thyroid cancer. Validation of this panel using a greater number of samples, samples from less invasive procedures and/or from various ethnic populations will need to be conducted in order to confirm the usefulness of this panel for clinical diagnosis. Further experiments are needed to develop diagnostic assays based on this panel to improve sensitivity for detection for use in a clinical setting. Moreover, our results suggest new molecular insights on thyroid cancer metastasis, especially for PTC, and thyroid cancer anoikis resistance in FTC, which can be novel potential targets for thyroid cancer treatment.

\section{Acknowledgements}

This study was partially funded by the New Researcher Grant from the Thailand Research Fund (TRG 5380025) and Chulabhorn Research Institute. We would like to express our gratitude to Professor Johan Lillehaug, University of Bergen, Norway, for providing us with thyroid cancer cell lines and to the Laboratory of Pharmacology, Chulabhorn Research Institute, for monoclonal antibodies for validation of the pathway.

\section{References}

1. International Agency for Research on Cancer: GLOBOCAN 2012: estimated cancer incidence, mortality and prevalence worldwide in 2012. World Health Organization. http://globocan. iarc.fr/Pages/fact_sheets_cancer.aspx. Accessed Sept 2, 2014.

2. Pellegriti G, Frasca F, Regalbuto C, Squatrito S and Vigneri R: Worldwide increasing incidence of thyroid cancer: update on epidemiology and risk factors. J Cancer Epidemiol 2013: 965212 , 2013.

3. Siegel R, Ma J, Zou Z and Jemal A: Cancer statistics, 2014. CA Cancer J Clin 64: 9-29, 2014.

4. Kondo T, Ezzat S and Asa SL: Pathogenetic mechanisms in thyroid follicular-cell neoplasia. Nat Rev Cancer 6: 292-306, 2006.

5. Parameswaran R, Brooks S and Sadler GP: Molecular pathogenesis of follicular cell derived thyroid cancers. Int J Surg 8: 186-193, 2010.
6. Barakate DM: Thyroid cancer prognosis. Thyroid Clinic Sydney. http://ww w.thyroid.com.au/thyroid-cancer/thyroidcancer-prognosis/2015. Accessed Sept 3. 2015.

7. Conzo G, Docimo G, Mauriello C, Gambardella C, Esposito D, Cavallo F, Tartaglia E, Napolitano S and Santini L: The current status of lymph node dissection in the treatment of papillary thyroid cancer. A literature review. Clin Ter 164: e343-e346, 2013.

8. Cooper DS, Doherty GM, Haugen BR, Kloos RT, Lee SL, Mandel SJ, Mazzaferri EL, McIver B, Pacini F, Schlumberger M, et al; American Thyroid Association (ATA) Guidelines Taskforce on Thyroid Nodules and Differentiated Thyroid Cancer: Revised American Thyroid Association management guidelines for patients with thyroid nodules and differentiated thyroid cancer. Thyroid 19: 1167-1214, 2009.

9. Hall TL, Layfield LJ, Philippe A and Rosenthal DL: Sources of diagnostic error in fine needle aspiration of the thyroid. Cancer 63: $718-725,1989$.

10. Moses W, Weng J, Sansano I, Peng M, Khanafshar E, Ljung BM, Duh QY, Clark OH and Kebebew E: Molecular testing for somatic mutations improves the accuracy of thyroid fine-needle aspiration biopsy. World J Surg 34: 2589-2594, 2010.

11. Krause K, Jessnitzer B and Fuhrer D: Proteomics in thyroid tumor research. J Clin Endocrinol Metab 94: 2717-2724, 2009.

12. Fan Y, Shi L, Liu Q, Dong R, Zhang Q, Yang S, Fan Y, Yang H, $\mathrm{Wu} \mathrm{P}, \mathrm{Yu} \mathrm{J}$, et al: Discovery and identification of potential biomarkers of papillary thyroid carcinoma. Mol Cancer 8: 79-93, 2009.

13. Brown LM, Helmke SM, Hunsucker SW, Netea-Maier RT, Chiang SA, Heinz DE, Shroyer KR, Duncan MW and Haugen BR: Quantitative and qualitative differences in protein expression between papillary thyroid carcinoma and normal thyroid tissue. Mol Carcinog 45: 613-626, 2006.

14. Giusti L, Iacconi P, Ciregia F, Giannaccini G, Donatini GL, Basolo F, Miccoli P, Pinchera A and Lucacchini A: Fine-needle aspiration of thyroid nodules: Proteomic analysis to identify cancer biomarkers. J Proteome Res 7: 4079-4088, 2008.

15. Subhasitanont P, Srisomsap C, Punyarit P and Svasti J: Proteomic studies of galectin-3 expression in human thyroid diseases by immunodetection. Cancer Genomics Proteomics 3: 389-394, 2006.

16. Srisomsap C, Subhasitanont P, Otto A, Mueller EC, Punyarit P, Wittmann-Liebold B and Svasti J: Detection of cathepsin B up-regulation in neoplastic thyroid tissues by proteomic analysis. Proteomics 2: 706-712, 2002.

17. Griffith OL, Chiu CG, Gown AM, Jones SJ and Wiseman SM: Biomarker panel diagnosis of thyroid cancer: A critical review. Expert Rev Anticancer Ther 8: 1399-1413, 2008.

18. Feilchenfeldt J, Tötsch M, Sheu S-Y, Robert J, Spiliopoulos A, Frilling A, Schmid KW and Meier CA: Expression of galectin-3 in normal and malignant thyroid tissue by quantitative PCR and immunohistochemistry. Mod Pathol 16: 1117-1123, 2003.

19. Volante M, Bozzalla-Cassione F, Orlandi F and Papotti M: Diagnostic role of galectin-3 in follicular thyroid tumors. Virchows Arch 444: 309-312, 2004.

20. Kebebew E, Peng M, Reiff E and McMillan A: Diagnostic and extent of disease multigene assay for malignant thyroid neoplasms. Cancer 106: 2592-2597, 2006.

21. Scognamiglio T, Hyjek E, Kao J and Chen Y-T: Diagnostic usefulness of HBME1, galectin-3, CK19, and CITED1 and evaluation of their expression in encapsulated lesions with questionable features of papillary thyroid carcinoma. Am J Clin Pathol 126: 700-708, 2006.

22. Viglietto $G$ and De Marco C: Molecular biology of thyroid cancer. In: Contemporary Aspects of Endocrinology. DiamantiKandarakis E (ed). InTech; c2011, pp189-234, 2011. http://www. intechopen.com/books/contemporary-aspects-of-endocrinology/ molecular-biology-of-thyroid-cancer.

23. Schlumberger MJ: Papillary and follicular thyroid carcinoma. $\mathrm{N}$ Engl J Med 338: 297-306, 1998.

24. Zaydfudim V, Feurer ID, Griffin MR and Phay JE: The impact of lymph node involvement on survival in patients with papillary and follicular thyroid carcinoma. Surgery 144: 1070-1077, discussion 1077-1078, 2008.

25. Woyach JA and Shah MH: New therapeutic advances in the management of progressive thyroid cancer. Endocr Relat Cancer 16: 715-731, 2009.

26. Morita N, Ikeda Y and Takami H: Clinical significance of p53 protein expression in papillary thyroid carcinoma. World J Surg 32: 2617-2622, 2008. 
27. Grogan $\mathrm{RH}$, Mitmaker EJ and Clark $\mathrm{OH}$ : The evolution of biomarkers in thyroid cancer-from mass screening to a personalized biosignature. Cancers (Basel) 2: 885-912, 2010.

28. Kim JW and Dang CV: Multifaceted roles of glycolytic enzymes. Trends Biochem Sci 30: 142-150, 2005.

29. Capello M, Ferri-Borgogno S, Cappello P and Novelli F: $\alpha$-Enolase: A promising therapeutic and diagnostic tumor target. FEBS J 278: 1064-1074, 2011.

30. Mikuriya K, Kuramitsu Y, Ryozawa S, Fujimoto M, Mori S, Oka M, Hamano K, Okita K, Sakaida I and Nakamura K: Expression of glycolytic enzymes is increased in pancreatic cancerous tissues as evidenced by proteomic profiling by twodimensional electrophoresis and liquid chromatography-mass spectrometry/mass spectrometry. Int J Oncol 30: 849-855, 2007.

31. Zhang XZ, Xiao ZF, Li C, Xiao ZQ, Yang F, Li DJ, Li MY, Li F and Chen ZC: Triosephosphate isomerase and peroxiredoxin 6 , two novel serum markers for human lung squamous cell carcinoma. Cancer Sci 100: 2396-2401, 2009.

32. Chang YS, Wu W, Walsh G, Hong WK and Mao L: Enolase- $\alpha$ is frequently down-regulated in non-small cell lung cancer and predicts aggressive biological behavior. Clin Cancer Res 9: 3641-3644, 2003.

33. Liu K-J and Shih N-Y: The role of enolase in tissue invasion and metastasis of pathogens and tumor cells. J Cancer Mol 3: 45-48, 2007. http://www.mupnet.com/jocm\%203\%282\%29\%2045-48. pdf.

34. Liaudet-Coopman E, Beaujouin M, Derocq D, Garcia M, Glondu-Lassis M, Laurent-Matha V, Prébois C, Rochefort $\mathrm{H}$ and Vignon F: Cathepsin D: Newly discovered functions of a longstanding aspartic protease in cancer and apoptosis. Cancer Lett 237: 167-179, 2006.

35. Dunn AD, Crutchfield HE and Dunn JT: Proteolytic processing of thyroglobulin by extracts of thyroid lysosomes. Endocrinology 128: 3073-3080, 1991

36. Kraimps J-L, Métayé T, Millet C, Margerit D, Ingrand $\mathrm{P}$, Goujon JM, Levillain P, Babin P, Begon F and Barbier J: Cathepsin D in normal and neoplastic thyroid tissues. Surgery 118: 1036-1040, 1995

37. Lokman NA, Ween MP, Oehler MK and Ricciardelli C: The role of annexin A2 in tumorigenesis and cancer progression. Cancer Microenviron 4: 199-208, 2011.

38. Mussunoor S and Murray GI: The role of annexins in tumour development and progression. J Pathol 216: 131-140, 2008.

39. Bao H, Jiang M, Zhu M, Sheng F, Ruan J and Ruan C: Overexpression of Annexin II affects the proliferation, apoptosis, invasion and production of proangiogenic factors in multiple myeloma. Int J Hematol 90: 177-185, 2009.
40. Sidani M, Wessels D, Mouneimne G, Ghosh M, Goswami S, Sarmiento C, Wang W, Kuhl S, El-Sibai M, Backer JM, et al: Cofilin determines the migration behavior and turning frequency of metastatic cancer cells. J Cell Biol 179: 777-791, 2007.

41. Wang W, Eddy R and Condeelis J: The cofilin pathway in breast cancer invasion and metastasis. Nat Rev Cancer 7: 429-440, 2007.

42. Zhu B, Fukada K, Zhu H and Kyprianou N: Prohibitin and cofilin are intracellular effectors of transforming growth factor $\beta$ signaling in human prostate cancer cells. Cancer Res 66: 8640-8647, 2006.

43. Maiti AK, Ghosh K, Chatterjee U, Chakrobarti S, Chatterjee S and Basu S: Epidermal growth factor receptor and proliferating cell nuclear antigen in astrocytomas. Neurol India 56: 456-462, 2008.

44. Cvejic D, Selemetjev S, Savin S, Paunovic I and Tatic S: Changes in the balance between proliferation and apoptosis during the progression of malignancy in thyroid tumours. Eur J Histochem 53: 65-71, 2009.

45. Feng L, Li M, Zhang Q-P, Piao Z-A, Wang Z-H and Lv S: Utility of BRAF protein overexpression in predicting the metastasis potential of papillary thyroid carcinoma. Oncol Lett 2: 59-63, 2011.

46. Tomsig JL, Sohma H and Creutz CE: Calcium-dependent regulation of tumour necrosis factor-alpha receptor signalling by copine. Biochem J 378: 1089-1094, 2004.

47. Tomsig JL, Snyder SL and Creutz CE: Identification of targets for calcium signaling through the copine family of proteins. Characterization of a coiled-coil copine-binding motif. J Biol Chem 278: 10048-10054, 2003.

48. Ramsey CS, Yeung F, Stoddard PB, Li D, Creutz CE and Mayo MW: Copine-I represses NF-kappaB transcription by endoproteolysis of p65. Oncogene 27: 3516-3526, 2008.

49. Parcellier A, Gurbuxani S, Schmitt E, Solary E and Garrido C: Heat shock proteins, cellular chaperones that modulate mitochondrial cell death pathways. Biochem Biophys Res Commun 304: 505-512, 2003.

50. Garrido C, Brunet M, Didelot C, Zermati Y, Schmitt E and Kroemer G: Heat shock proteins 27 and 70: Anti-apoptotic proteins with tumorigenic properties. Cell Cycle 5: 2592-2601, 2006.

51. Lebret T, Watson RWG, Molinié V, O'Neill A, Gabriel C, Fitzpatrick JM and Botto H: Heat shock proteins HSP27, HSP60, HSP70, and HSP90: Expression in bladder carcinoma. Cancer 98: 970-977, 2003

52. Paoli P, Giannoni E and Chiarugi P: Anoikis molecular pathways and its role in cancer progression. Biochim Biophys Acta 1833: 3481-3498, 2013 